\title{
Thymoquinone attenuates cisplatin-induced hepatotoxicity via nuclear factor kappa- $\beta$
}

\author{
Abdulrahman L Al-Malki ${ }^{1 *}$ and Ahmed Amir Radwan Sayed ${ }^{1,2}$
}

\begin{abstract}
Background: Cisplatin (CP) is known as a potent anti-cancer drug. The most therapeutic adverse effect of CP is induced hepatotoxicity. In the present study, the protective effect of thymoquinone (TQ) on CP-induced hepatotoxicity was studied.

Methods: Wistar rats were divided into three groups (15 rats each). Group 1 served as the control group. Group 2 rats were injected ip with a single dose of CP $(12 \mathrm{mg} / \mathrm{kg}$ b.w, i.p.). Group 3 rats were orally pre-treated with TQ (500 mg. $\mathrm{kg}^{-1}$. day ${ }^{-1}$ ) for one month, then the animals were injected i.p with CP $12 \mathrm{mg} \cdot \mathrm{kg}^{-1}$.

Results: The beneficial effects of TQ with its antioxidant/anti-inflammatory effects were observed. Injection of rats with CP markedly affected the liver functions and histopathological changes. The antioxidant enzyme activities and reduced glutathione (GSH) contents were significantly decreased while the levels of malondialdehyde (MDA) significantly increased. The electromobility shift assay (EMSA) showed a significant activation of NF-KB-p65 in the rat liver injected with CP. Furthermore, the expression and concentrations of inflammatory tumor necrosis factor (TNF-a), nitric oxide synthetase (iNOS), and interleukin (IL-1 $\beta$ ) were markedly elevated in the CP injected rats. The administration of TQ improved all the altered functions, histopathology of the liver and attenuated the activated NF-KB. The antioxidant enzyme activities (glutathione peroxidase and glutathione $-S$ transferase) of the rat livers were markedly increased while MDA was reduced as a result of TQ administration. In addition, the expression of TNF- $a$, iNOS, and IL-1 $\beta$ were markedly reduced.
\end{abstract}

Conclusion: It was concluded that, TQ has potential benefits in the prevention of the onset and progression of CP induced hepatotoxicity.

Keywords: Nigella Sativa, NF-KB, CP, hepatotoxicity, TNFa, IL-1ß

\section{Background}

The modern life style and environmental pollution, have been the causes of increased cancer burdens in the world. Chemotherapy is one of the most important methods used in cancer therapy. CP [cis-diamminedichloroplatinum (II)] $(\mathrm{CP})$ is a well known anticancer drug. It is primarily used as a drug in the treatment of solid tumors. Use of $\mathrm{CP}$ in the treatment of tumors is restricted due to its toxic effect on kidney and liver, which can be seen after a single dose of CP in approximately $28 \%$ to $36 \%$ of cancer patients [1]. $\mathrm{CP}$ is a small molecule which can easily cross the plasma membrane and then to nucleus. In the nucleus, $\mathrm{CP}$ causes changes in the structure of the DNA molecule. These changes result from the formation of inter- and intra-

\footnotetext{
* Correspondence: alalmalki@kau.edu.sa

'Department of Biochemistry, Faculty of Science, King Abdulaziz University,

P.O Box 80203, Jeddah, Saudi Arabia

Full list of author information is available at the end of the article
}

chain adducts between $\mathrm{CP}$ and the nitrogen bases of the DNA [2]. Oxidative stress plays the key role in the CP induced hepatotoxicity. Previous studies showed that, the earliest signs of $\mathrm{CP}$ induced hepato-toxicity are the fall in the hepatic reduced glutathione (GSH) levels and an increase in the hepatic malondialdehyde (MDA) levels [3]. These signs indicate the acceleration of the peroxidative processes in the hepatic cell $[4,5]$.

The oxidative stress and production of reactive oxygen species (ROS) such as hydroxyl radicals, superoxide anions, and hydrogen peroxide are normally generated in liver. A detoxification mechanism working in the liver detoxifies the ROS by endogenous antioxidants such as GSH, SOD, and catalase. The accumulation of intracellular ROS leads to an increase in both DNA damage and peroxidation of membrane lipids [4]. 
The exogenous production of free radicals may originate from different factors such as pollution of water and air and radiation exposure. Further, endogenous free radical production results from normal metabolism. Many chronic diseases, like cancer, diabetes, Alzheimer, and cardiovascular diseases are associated with free radical production. Free radicals are highly reactive intermediates. They react with nucleotides of DNA, the sulphhydryl bonds of protein, and the polyunsaturated fatty acids found in cellular membranes that result in tissue damage [6]. Prevention and/or decreasing of the side effects of CP are of the main concerns in treating patients suffering from cancer. Different methods were established to attenuate the toxic effects of $\mathrm{CP}$, such as combination of the free radical scavengers [7] but it is not efficient.

Thymoquinone (TQ) is a phytochemical that has been reported to exhibit antimicrobial effects against different species of bacteria. TQ is considered as potent anti-oxidant, anti-carcinogenic and anti-mutagenic agent. Moreover, TQ is a relatively safe compound, particularly when given orally to experimental animals [8].

TQ is a quinone isolated from Nigella sativa seeds. Previous study showed that TQ has a significant protective action toward an array of free radical creating compounds like doxorubicin [9]. In addition TQ has an antiinflammatory as well as an analgesic action and protects against carcinogenesis induced by different chemical compounds [10]. Moreover, TQ has protective effect against both diabetic nephropathy [11-13] and membrane induced lipid peroxidation [8]. Furthermore, it has been showed that TQ is a potent suppressor of iron-NTA induced oxidative stress and carcinogenesis in the rat kidney [14].

The aim of the present study is to evaluate the protective effects of TQ on the CP-induced hepatotoxicity in rats. In addition, the mechanism of action of TQ was studied to show the impact of oxidative stress as well as the antioxidants in the development and attenuation of $\mathrm{CP}$-induced hepatotoxicity.

\section{Methods}

\section{Chemicals}

Thymoqunione (TQ) was purchased from Sigma-Aldrich (St. Louis, MO, USA). BCA mega kit (Pierce, Rockford, USA). All assay kits were obtained from BIORAD (England). Primers were obtained from Bioline Inc., (Taunton, MA, USA). Monoclonal antibody, anti- NFkBp were obtained from Bioline Inc. All the chemicals used in the study were of analytical grade.

\section{Animals}

Male Wister rats weighting $190 \pm 30 \mathrm{~g}$ were kept for 7 days with free access to water ad libitum and standard rat chow.
All the animal protocol was approved from the University Animal Ethics committee. CEGMR committee licensee \# at KASCT. HA-02 J-003.

Rats were randomly divided into three groups each consists of 15 rats. Group 1 served as the normal control group. Animals of this group were treated with normal saline intrapertoneal (ip). Group 2 was injected i.p. with a single dose of CP (12 mg/kg b.w, i.p.) obtained from Sigma (England). Group 3 was orally pre-treated with TQ in polypropylene glycol (500 mg. $\mathrm{kg}^{-1}$. day ${ }^{-1}$ ) [12] for one month, then the animals were injected i.p. with CP 12 mg. $\mathrm{kg}^{-1}$ body weight [15]. TQ treatment was continued for one month. At the end of the experiment, rats were sacrificed, the blood was collected, and serum was separated and stored at $-80^{\circ} \mathrm{C}$. Serum was used for the determination of serum lactate dehydrogenase (LDH), alanine amino transferase (ALT), үGGT, aspartate amino transferase (AST), total protein (t. Protein) alkaline phosphatase (ALP), albumin, and total bilirubin.

Liver was isolated and rinsed carefully with cold normal saline and divided into four parts. The first part was used to prepare the tissue homogenate in phosphate buffered saline (50 mmol/l, pH 7). The liver homogenate was used for the assay of the activity of superoxide dismutase (SOD), catalase, glutathione peroxidase (GSH-Px), glutathione $S$ transferase (GST), and the levels of reduced glutathione (GSH), malondialdehyde (MDA), NO, IL-1 $\beta$ and TNF $\alpha$. The second part of the liver was used in the preparation of the tissue extract for electromobility shift assay (EMSA) analysis. Total RNA was extracted from the third part of the liver and the fourth part was used for histopathological examinations.

\section{Assay of ALT, AST, ALP, t. protein, albumin, t. bilirubin, and YGGT}

ALT, ALP, AST, albumin, t. protein, yGGT and t. bilirubin in the serum of all rats were assayed using the available kits obtained from Bio Vision Research Products (Avenue, USA). All assays were made according to the instructions of the manufacturer.

\section{Determination of LDH}

The method of King [16] was used for the assay of LDH using kit from BIORAD (England).

\section{Assay of reduced GSH}

Reduced GSH was assayed by the colorimetric end point method as described by Sayed [17] using kit from BIORAD (England).

\section{Determination of the activity of glutathione peroxidase}

The method of Paglia and Valentine [18] was used for the determination of the activity of glutathione peroxidase in 
the liver homogenate using kit from BIORAD (England). The activity was expressed as $\mathrm{U} / \mathrm{mg}$ protein.

\section{Assay of GST activity}

The activity of GST was determined as described by Moron et al. [19] by using 1-chloro -2, 4- dinitro benzene (CDNB) as an electrophilic substrate using kit from BIORAD (England). The activity was expressed as $\mathrm{nmol} /$ mg protein.

\section{Assay of malondialdehyde (MDA)}

Malondialdehyde (MDA) was assayed using the method described $[20,21]$. The concentration of MDA was calculated and expressed as $\mathrm{nmol} . \mathrm{mg}^{-1}$ protein.

\section{Assay of the activity of SOD}

The activity of super oxide dismutase was assayed as described [22] using kit from BIORAD (England). The activity was expressed as $\mathrm{U} / \mathrm{mg}$ protein.

\section{Assay of the nitric oxide concentration}

The formation of $\mathrm{NO}$ was determined by indirect method by quantifying the tissue level of nitrite by a calorimetric method by Griess reaction [23] using kit from BIORAD (England).

\section{Assay of IL-1 $\beta$ and TNF- $\alpha$}

$I L-1 \beta$ and TNF- $\alpha$ levels were assayed using an available ELISA kit from R \& D (Berlin, Germany) according to the manufacturer's instructions [24]. Protein concentration in the liver homogenate was assayed using BCA mega kit (Pierce, Rockford, USA).

\section{RT-PCR}

The transcripts were amplified in a single reaction containing $1 \mathrm{mg} \mathrm{cDNA}$ and $0.5 \mathrm{mM}$ each of the sense and antisense primers for IL-1 $\beta$ ( sense $5^{\prime}$ - AT GG CA AC TG TC CC TG AA CT C -3'; antisense 5'- GT CG TT GC TT GT CT CT CC TTG -3' ), TNFa sense 5'TCATGCACCACCATCAAGGA-3' and antisense 5'GA CA TT CG AG GC TC CA GT GA A - $3^{\prime}$ and iNOS sense $5^{\prime}$-CA GC CA AG TA TT CC AA AG CA A $-3^{\prime}$ and antisense $5^{\prime}$ - AG TC CA GT CC CC TC AC CA A - $3^{\prime}$; $\beta$ - actin sens $5^{\prime}$ GT GC TA TG TT GC TC TA GA CT TC G - $3^{\prime}$, antisens 5' AT GC CA CA GG AT TC CA TA $\mathrm{CC}-3^{\prime}$ were obtained from BIOLINE Inc., (Taunton, MA, USA).

The cycle consistes of preheating step at $95^{\circ} \mathrm{C}$ for $5 \mathrm{mi}-$ nute followed by 35 cycles of $90^{\circ} \mathrm{C}$ for 1 minute, and $60^{\circ} \mathrm{C}$ for 30 seconds.

\section{EMSA analysis}

Part of the liver was dissolved in TOTEX buffer. The extract was used for determination of the binding activity using NF-kBp65 consensus sequence: $5^{\prime}$-AG TT GA GG GG AC TT TC CC AG GC -3' which was obtained from BIOLINE Inc. (Taunton, MA, USA). The increase in the expression of NFkBp65 gene was determined by a Phosphor Imager using background subtraction [25].

\section{Histopathological examination}

Liver tissues were collected from rats, washed carefully by cold normal saline 3 times, then fixed in formalin solution $10 \%$, processed, and embedded in a paraffin film. Sections of 5- $\mu \mathrm{m}$ thick slices of liver were prepared. The sections were stained with $\mathrm{H} \& \mathrm{E}$. The method was described in Fukuzawa et al. [26].

\section{Immunohistochemistry}

The sections of tissues in phosphate-buffered saline $(\mathrm{pH}=7.2)$ were incubated overnight at $4^{\circ} \mathrm{C}$ with the respective primary monoclonal antibody, and anti- NFkBp dilutions (1:100, 1:50). Immunohistochemical staining was performed by the streptavidin-biotin complex method. All sections were then counterstained with hematoxylin.

\section{Statistical analysis}

All values are expressed as the mean $\pm \mathrm{SD}$. Data were evaluated by using SPSS for windows. The one way ANOVA test was used to examine whether there are any significant differences between the treatment groups, and the value of $P<0.05$ was considered significant.

\section{Results}

Initial and final body weights

Both the initial and the final body weights of all rats are presented in Table 1 . There were no significant differences in the initial body weights among all three groups. Rats treated with CP (group 2) showed a significant decrease in the final body weights (group 2) when compared to the

Table 1 Biochemical parameters of liver function tests as well as initial and final body weights of rat

\begin{tabular}{llll}
\hline & Group 1 & Group 2 & Group 3 \\
\hline Initial body weight, g & $210 \pm 10$ & $203 \pm 12$ & $201 \pm 12$ \\
Final body weight, g & $243 \pm 18$ & $172 \pm 12^{\mathrm{a}}$ & $225 \pm 12^{\mathrm{b}}$ \\
ALT, U/L & $29.12 \pm 1.12$ & $98.32 \pm 2.3^{\mathrm{a}}$ & $39.2 \pm 1.3$ \\
AST, U/L & $26.78 \pm 1.5$ & $90.78 \pm 1.14^{\mathrm{a}}$ & $48.5 \pm 5.3$ \\
ALP, U/L & $167.34 \pm 2.32$ & $369.12 \pm 18.8^{\mathrm{a}}$ & $215.3 \pm 11.2^{\mathrm{b}}$ \\
LDH, U/L & $75.67 \pm 2.12$ & $155.56 \pm 2.4^{\mathrm{a}}$ & $112 \pm 4.2^{\mathrm{b}}$ \\
YGGT, U/L & $59.36 \pm 1.45$ & $109.5 \pm 2.43^{\mathrm{a}}$ & $85 \pm 3.5$ \\
t. protein, mg\% & $9.53 \pm 0.76$ & $6.15 \pm 1.27$ & $6.8 \pm 2.1$ \\
Albumin, mg\% & $3.94 \pm 0.98$ & $2.4 \pm 0.54^{\mathrm{a}}$ & $4.65 \pm 2.5^{\mathrm{b}}$ \\
t. Bilirubin, mg\% & $0.75 \pm 0.05$ & $1.6 \pm 0.23^{\mathrm{a}}$ & $1.1 \pm 0.01^{\mathrm{b}}$ \\
\hline
\end{tabular}

Values are expressed as mean \pm S.D. of triplicate tests $(n=15)$.

${ }^{\mathrm{a}} P<0.05$ vs group $1,{ }^{\mathrm{b}} \mathrm{P}<0.05$ vs group 2 .

The effect of TQ on the liver function parameters of different groups. 
control group. As a result of TQ treatment, the rats of group 3 showed a significant increase in the final body.

\section{Effect of CP and TQ administration on the hepatic biomarkers}

Table 1 shows that the injection of $\mathrm{CP}$ significantly increased the hepatic levels of ALT, ALP, AST, үGGT, total bilirubin and LDH and a significant decrease of serum albumin when compared to the control group. Administration of TQ significantly improved the negative effects of some of the hepatic biomarkers and modulated the other toxic effects.

\section{Effect of TQ administration on glutathione peroxidase activity}

As a result of CP treatment, the activity of GSH-px in the liver tissue of the rats in group 2 was significantly reduced when compared with the control group (group 1) (Table 2). On the other hand, treatment of rats in group 3 with TQ resulted in a marked increase of GSH-px activity when compared to the $\mathrm{CP}$ treated rats (group 2) $(P<0.05)$.

\section{Effect of TQ administration on superoxide dismutase activity}

SOD plays an important role in detoxification of the hydroxyl radicals. The activity of SOD in the liver homogenates of all experimental rats is shown in Table 2. In group 2, treatment of rats with $\mathrm{CP}$ reduced the SOD activity compared to the control group. Enhancement of SOD activity was observed as a result of TQ treatment, and the activity was found to be markedly increased.

\section{Effect of administration of TQ on glutathione-S-transferase activity}

Table 2 shows a significant decrease in the hepatic GST activity upon $\mathrm{CP}$ treatment as compared to the control group $(P<0.05)$. A significant increase in GST activity was observed in the rat group treated with TQ as compared to the CP treated group $(P<0.05)$.

Table 2 Antioxidant parameters of rat liver

\begin{tabular}{llll}
\hline & Group 1 & Group 2 & Group 3 \\
\hline MDA, nmol/mg protein & $0.52 \pm 0.06$ & $5.1 \pm 0.85^{\mathrm{a}}$ & $0.95 \pm 0.02^{\mathrm{b}}$ \\
GSH, nmol/mg protein & $111 \pm 5.8$ & $55.9 \pm 4.6^{\mathrm{a}}$ & $89.5 \pm 2.1^{\mathrm{b}}$ \\
GST, nmol/mg protein & $18.6 \pm 1.5$ & $6.29 \pm 0.39^{\mathrm{a}}$ & $14.76 \pm 0.86^{\mathrm{b}}$ \\
$\mathrm{SOD}, \mathrm{U} / \mathrm{mg}$ protein & $15.8 \pm 1.1$ & $9.6 \pm 2.1^{\mathrm{a}}$ & $14.25 \pm 1.1^{\mathrm{b}}$ \\
CAT, U/mg protein & $5.95 \pm 0.5$ & $2.41 \pm 0.31^{\mathrm{a}}$ & $4.56 \pm 0.54^{\mathrm{b}}$ \\
GSH-Px, U/mg protein & $4.95 \pm 0.21$ & $2.05 \pm 0.12^{\mathrm{a}}$ & $4.67 \pm 0.65^{\mathrm{b}}$
\end{tabular}

The expressed values are mean \pm S.D. of triplicate tests $(n=15)$.

${ }^{\mathrm{a}} P<0.05$ vs group $1,{ }^{\mathrm{b}} P<0.05$ vs group 2 .

The activity of the antioxidant enzymes as well as the levels of MDA and GSH in the liver homogenates of different groups.

\section{Effect of TQ administration on glutathione levels}

CP treatment significantly decreased GSH level in the liver tissue homogenates compared to the control group. Rats treated with CP had a lower GSH content than the normal control group. Administration of TQ significantly modulated these alterations and the level of GSH rose $(\mathrm{P}<0.05)$ as shown in Table 2.

\section{Effect of administration of TQ on lipid peroxidation}

Formation of free radicals and induction of oxidative stress is a direct cause of lipid peroxidation. Lipid peroxidation was measured as MDA in rat liver homogenate and the results are shown in Table 2. After $12 \mathrm{mg} / \mathrm{kg} \mathrm{CP}$ injection, the liver MDA level significantly increased. Administration of TQ significantly decreased the amount of MDA in the CP treated rats of group 3. The oral administration of TQ decreased the level of MDA.

\section{Effect administration of TQ on catalase activity}

As a result of $\mathrm{CP}$ injection, catalase activity was markedly reduced. Table 2 shows that the activity of catalase was reduced in the CP treated group. However, the oral administration of TQ increased the activities.

\section{Effect of CP and TQ treatment on NO, TNFa and IL-1 $\beta$}

The effect of CP as well as the effect of TQ on NO, TNFa and IL-1 $\beta$ in rats was studied. Figure 1 shows that the level of NO was markedly and dose dependently increased as a result of CP treatment. Administration of TQ reversed these effects and significantly reduced the levels of NO in the treatment group 3 (Figure 1A).

The levels of TNF $\alpha$ and IL-1 $\beta$ were significantly and dose dependently elevated in the $\mathrm{CP}$ treated rats (group 2) as indicated in Figure $1 \mathrm{~B}$ and $\mathrm{C}$. The elevated levels of TNF $\alpha$ and IL-1 $\beta$ were significantly reduced as a result of TQ administration.

NF-kB-p65 was markedly activated in the CP treated animals compared with the control. Administration of TQ resulted in a significant reduction in the of NF- $k B-$ p65 in a dose dependent manner (Figure 2).

As a result of oxidative stress, NF-kB-p65 was markedly activated in the cisplatin treated animals compared with the normal control. Administration of TQ resulted in a significant reduction of the of NF-kB-p65 activation. The levels of TNF $\alpha$ and IL-1 $\beta$ were significantly and dose dependently elevated in the $\mathrm{CP}$ treated rats (group 2) as indicated in Figure 1B and C. The elevated levels of TNF $\alpha$ and IL-1 $\beta$ were significantly reduced as a result of TQ administration (Figure 3).

Rats which received cisplatin showed a significant increase in the immunoreactivity of NF- $\mathrm{kB}$ in the cytoplasm of hepatocytes compared with the normal control group. On the other hand, thymoquinone-treated rats showed considerable reduction in the cisplatin-induced expression 

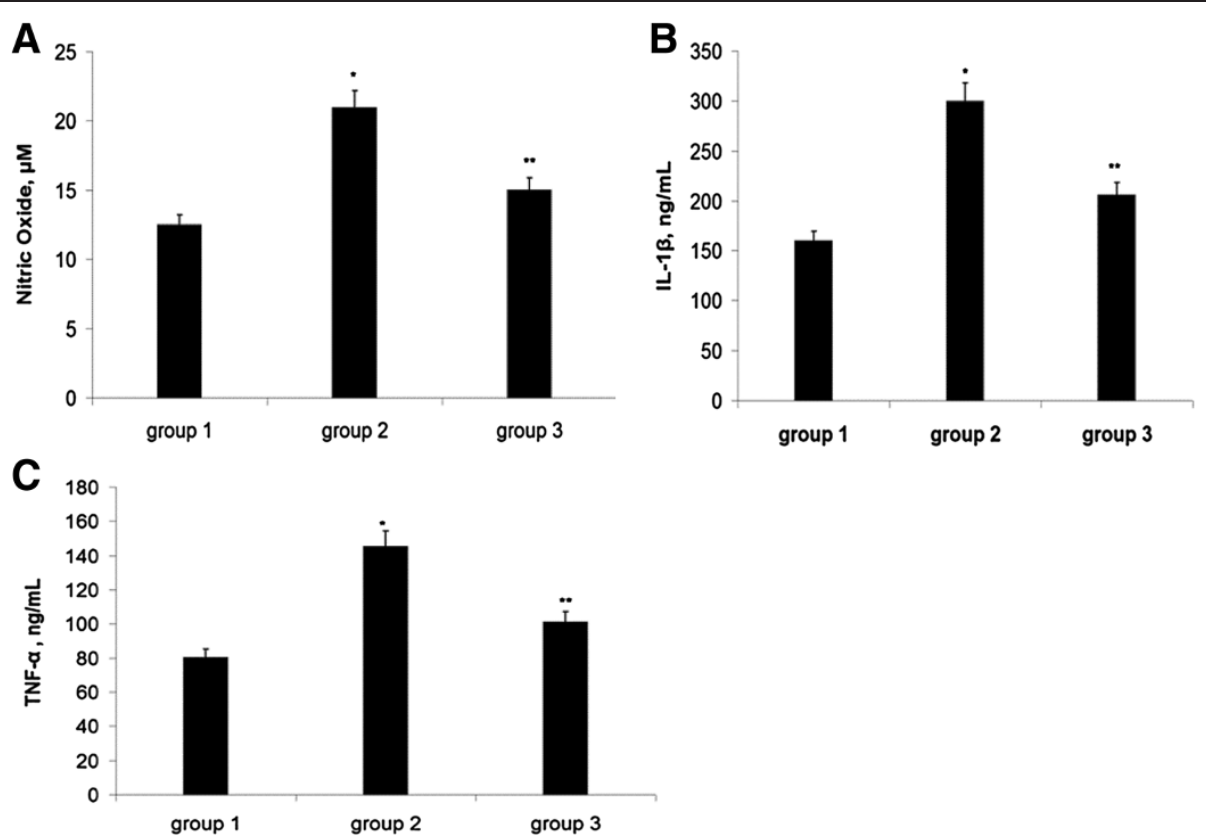

Figure 1 Effect of TQ on the levels of nitric oxide (A), IL1- $\beta$ (B), and TNFa (C) of CP treated rats. Results are presented as mean \pm SD, ${ }^{*} \mathrm{P}<0.05$ against group $1,{ }^{* *} \mathrm{P}<0.05$ against group 2 .

of NF- $\mathrm{kB}$ in the liver compared with the cisplatin treated rats group 2 (Figure 4D-F).

\section{Discussion}

Thymoquinone (TQ) showed diverse therapeutic benefits as related to bronchial asthma, dysentery, headache, gastrointestinal problems, eczema, hypertension, and obesity, antiproliferative effects on cell lines derived from breast, colon, ovarian, larynx, lung, myeloblastic leukemia, and osteosarcoma. Mechanistically, TQ induced apoptosis in tumor cells by suppressing NF-kB, Akt activation, and extracellular signal-regulated kinase signaling pathways and also suppress tumor angiogenesis. These studies suggested that TQ is useful as conventional chemotherapeutics against cisplatin induced cytotoxicity. It was found that, TQ was effective as inducer of apoptosis in some

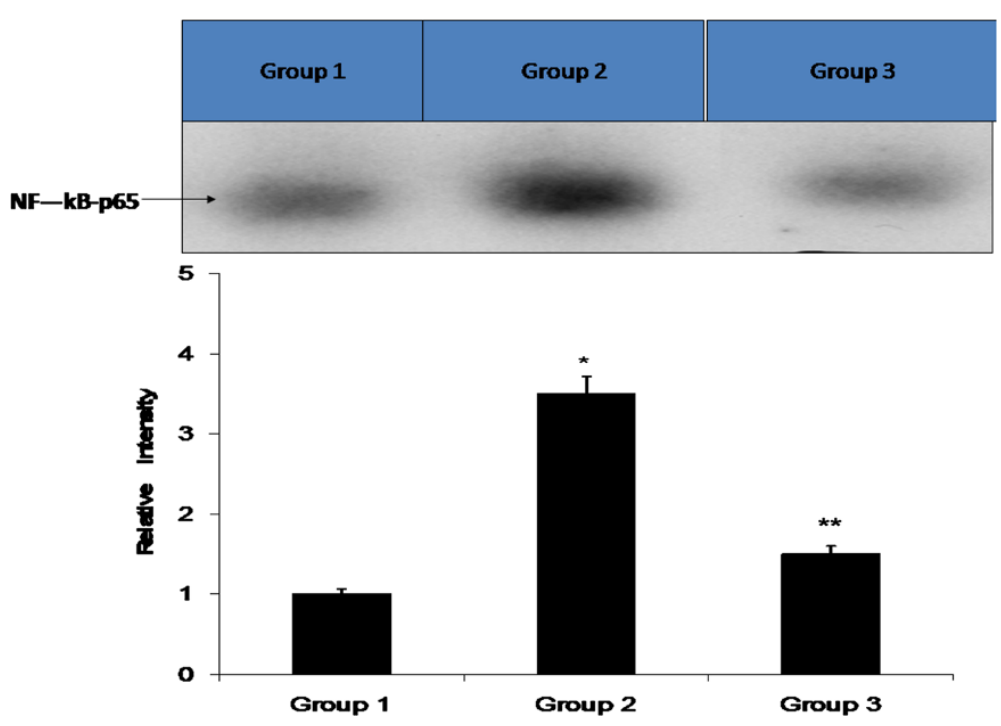

Figure 2 Binding activity of NF- $\mathbf{K B}$. Quantification of activated NF-kB was performed by densitometric analysis of relative EMSA band intensities. Results are the means \pm SE of four individual replicates; value from an unpaired Student's $t$-test $\left({ }^{*} P<0.05\right.$, compared with group 1 and $\left.{ }^{* *} P<0.001\right)$ comparing with group 2 . 

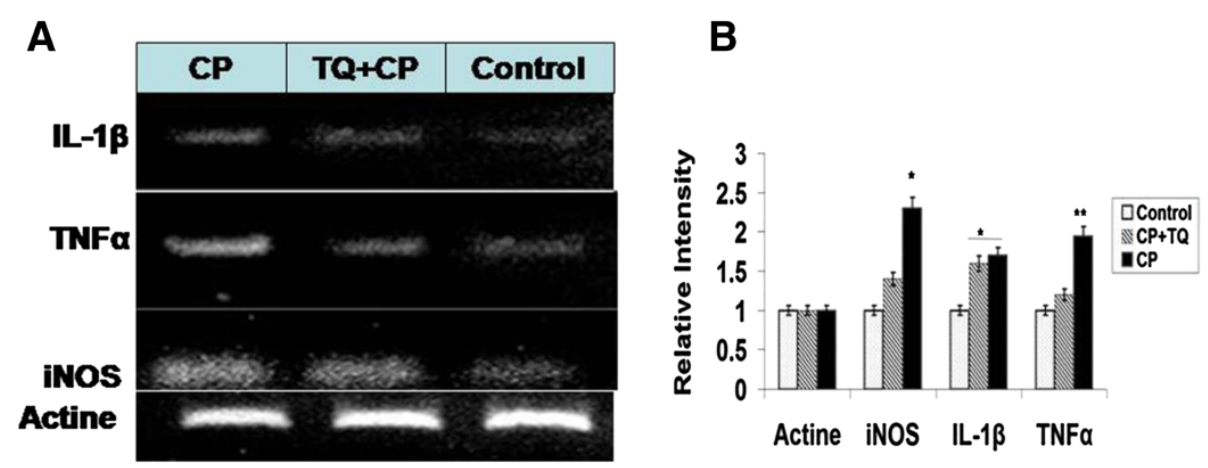

Figure 3 Effect of CP on IL1- $\beta$, TNF- $\alpha$ and iNOS expression (A). The relative intensity of the bands is represented in (B) Data are the mean \pm S.D. (n15); ${ }^{*} P<0.01,{ }^{*} P<0.01$ vs. control animals.

types of cancer by down-regulating several antiapoptotic proteins such as Bcl-xL [9].

The hepatic cell contains high levels of transaminases as AST. As a result of the damage caused to hepatic cells by $\mathrm{CP}$, the leakage of cytosol resulted in increasing levels of the liver specific enzymes in the rat serum. The elevated levels of the hepatic enzymes in the serum such as AST and ALT are markers that indicate the cellular leakage and the functional integrity of the liver cell membrane [27]. The serum levels of ALT and AST serve as a indirect assessment of the condition of the liver. In the present study, the capability of TQ in ameliorating the CP-induced hepatotoxicity was observed in that the rats of group 3 had lower levels of the hepatic enzyme in the serum when compared with the animals of group 2 .

TNF- $\alpha$ is a pro-inflammatory cytokine. Its levels are elevated in the acute and chronic disease conditions. The anti-inflammatory action of TQ was estimated in vivo by measuring the release of TNF- $\alpha$. Previous studies showed that natural products have the ability to reduce inflammation by blocking the inflammatory mechanisms downstream of the release of cytokines, and also by attenuating the production of the proinflammatory factors by macrophage [28]. It was reported that the proinflammatory cytokines like TNF- $\alpha$ play an important role in the pathogenesis of a large number of liver diseases. TNF- $\alpha$ is released from the activated Kupffer cells. Following its release, it aggravates both the inflammatory response and oxidative stress in the hepatic cells [29]. In addition, it induces the production and release of chemokines and cytokines from macrophages and stimulates phagocyte nitric oxide (NO) production and oxidative metabolism. Although previous studies showed that the production of NO protects the liver from injury by a NOS inhibitor, recent data shows that the excessive production of nitric oxide by iNOS can result in hepatic injury [30]. A recent report showed that

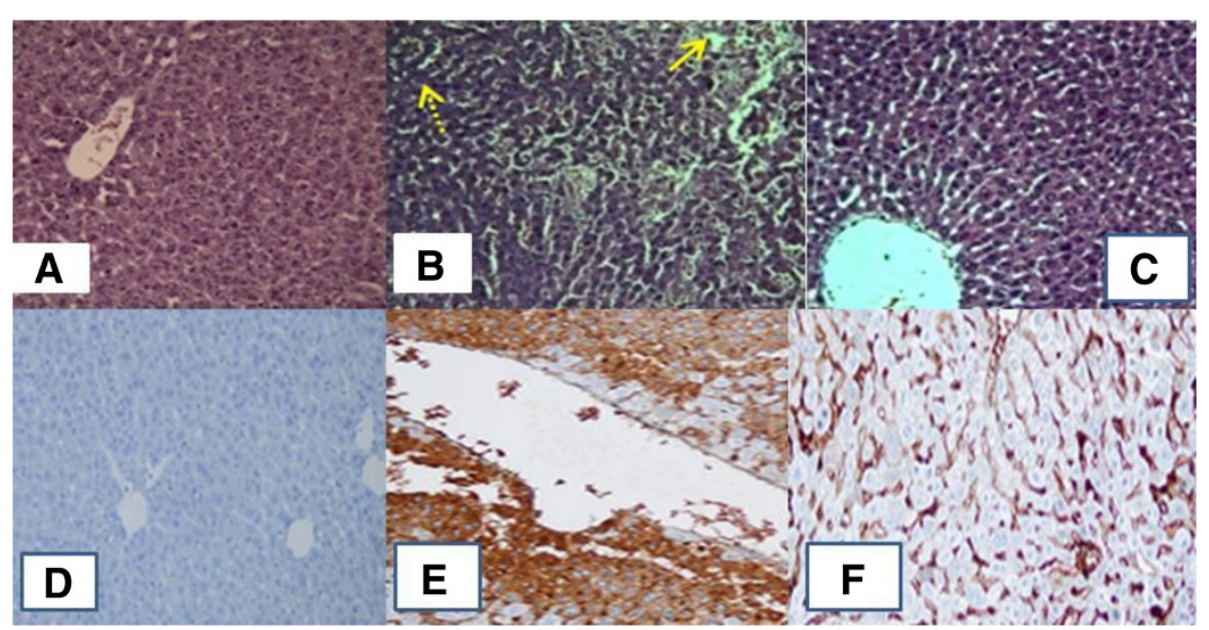

Figure 4 Histopathological and immunohistochemical observation of rat liver sections Vacuolar degeneration (dotted arrows) and hepatocellular necrosis (complete arrows) are displayed). (A): Control group; (B): group treated $12 \mathrm{mg} / \mathrm{kg}$ cisplatin; (C): group pretreated with thymoquinone then cisplatin as discussed in methods. Immunohistochemical staining of NF-KB in rat from: (D, 200) group 1, showing no expression of NF-KB; (E, 200) group 2 showing a significant increase in NF-KB immunoreactivity in the cytoplasm of hepatocytes; and (F, 200) group 3 demonstrating a significant reduction in NF-KB immunostaining. 
the overproduction of iNOS in the rat liver is related in the acute liver injury. This suggested that iNOS could act as a mediator in the pathogenesis of the liver toxicity in rats [31].

In this study, we showed that the liver protective effect of TQ was not only attributed to its inhibitory effect on the release of the inflammatory mediators NO, TNF- $\alpha$, and IL-1 $\beta$, but also to its antioxidant properties. MDA, a product of lipid peroxidation, was increased in the rat liver as a result of $\mathrm{CP}$ injection. However, we showed that TQ significantly reduced MDA formation. In other words, the mechanism of the inhibitory effects, by which TQ protects against lipid peroxidation, may involve radical scavenging capability. Hepatotoxicity not only initiates lipid peroxidation but also reduces tissue GSH-px, GST, CAT, and SOD activities, and this depletion may result from oxidative modification of these proteins and our data are in line with other previous studies [32-36].

$\mathrm{NF}-\mathrm{kB}$ is a nuclear transcription factor found in the cytoplasm of the liver cells. In the cytoplasm, it binds to its inhibitory subunit $\mathrm{I}-\mathrm{k} \mathrm{B}$. As a result of oxidative stress, NFkB is activated and phosphorylated from its inhibitory subunit. As a result of its activation, NF- $\mathrm{kB}$ transfers to the nucleus of the hepatic cell, binds to DNA and upregulates the transcription of many inflammatory genes like cytokine, chemokine and receptors of advanced glycation end products [31]. Our data from the EMSA and immunohistochemistry showed a marked activation of $\mathrm{NF}-\mathrm{kB}$ which are in line with the hypothesis above. In addition the data on the levels of TNF- $\alpha$, NO and IL-1 $\beta$ and the expression of the TNF- $\alpha$, iNOS and IL- $1 \beta$ genes support the results of the EMSA and immunohistochemistry. Our study is in accordance with the study that reported that TQ induced apoptosis in tumor cells by suppressing NF-kB, Akt activation, and extracellular signal-regulated kinase signaling pathways and suppressing tumor angiogenesis. These studies suggested that TQ is useful as conventional chemotherapeutics against cisplatin induced cytotoxicity. It was found that TQ was effective as inducer of apoptosis in some types of cancer by down-regulating several antiapoptotic proteins such as Bcl-xL. For this reason black Nigella seeds is widely used in baking of bread and other foods, as additive for spiced and flavored and aromatic substances. Nigella seeds are reported as antifungal, antibacterial, antiviral and antihelmintic, treatment of flatulence and abdominal ailments, decrease fasting plasma glucose concentration in rabbit, increase serum total protein, as diuretic, hepatoprotective and hypotensive.

The present study clearly demonstrates that controlling of oxidative stress and catalytic reactive oxygen scavenging are effective in the prevention of $\mathrm{CP}$ induced hepatotoxicity. TQ is the major constituent of the natural food supplement (Nigella sativa) with a broad spectrum of beneficial biochemical and cellular biological effects, based on its ability to reduce inflammation and ROS overproduction. Since TQ also has beneficial effects on other target tissues and shows beneficial effects of mediators of large vessel damage, this mechanism appears attractive for the prevention or delay of many disorders.

\section{Conclusion}

Our findings show that TQ has the potential benefits in the prevention of the onset and progression of CP induced hepatotoxicity.

\section{Competing interests}

The authors certify that there is no actual or potential conflict of interest in relation to this article.

\section{Authors' contributions}

ALA: Contribution to design, preparation of draft, data analysis, interpretation and final approval of the version for publishing. AAR: Involved in conception, drafting the manuscript and revising it critically. Both authors read and approved the manuscript.

\section{Acknowledgment}

This work was funded by the Deanship of Scientific Research (DSR), King Abdulaziz University, Jeddah, under grant No. (130-005-D1433). The author, therefore, acknowledge with thanks DSR technical and financial support.

\section{Author details}

${ }^{1}$ Department of Biochemistry, Faculty of Science, King Abdulaziz University, P.O Box 80203, Jeddah, Saudi Arabia. ${ }^{2}$ Chemistry Department, Faculty of Science, Minia University, El- Minia, Egypt.

Received: 7 May 2014 Accepted: 25 July 2014

Published: 3 August 2014

\section{References}

1. Lebwohl D, Canetta R: Clinical development of platinum complexes in cancer therapy: an historical perspective and an update. Eur J Cancer 1998, 34:1522-1534.

2. Hah SS, Stivers KM, de Vere RW, Henderson PT: Kinetics of carboplatin DNA binding in genomic DNA and bladder cancer cells as determined by accelerator mass spectrometry. Chem Res Toxicol 2006, 19:622-626.

3. Pugh CW, Ratcliffe PJ: Regulation of angiogenesis by hypoxia: role of the HIF system. Nat Med 2003, 9:677-684.

4. Kumari KK, Setty $\mathrm{OH}$ : Protective effect of Phyllanthus fraternus against mitochondrial dysfunction induced by co-administration of CP and cyclophosphamide. J Bioenerg Biomembr 2012, 44:179-188.

5. Kaushal GP, Kaushal V, Hong X, Shah SV: Role and regulation of activation of caspases in CP-induced injury to renal tubular epithelial cells. Kidney Int 2001, 60:1726-1736.

6. Turkez H, Geyikoglu F, Yousef Ml, Celik K: Ameliorative effect of supplementation with L-glutamine on oxidative stress, DNA damage, cell viability and hepatotoxicity induced by 2,3,7,8-tetrachlorodibenzop-dioxin in rat hepatocyte cultures. Cytotechnology 2012, 64:687-699.

7. Davis CA, Nick HS, Agarwal A: Manganese superoxide dismutase attenuates $\mathrm{CP}$-induced renal injury: importance of superoxide. J Am Soc Nephrol 2001, 12:2683-2690.

8. Houghton PI, Zarka R, Heras BD, Hoult RS: Fixed oil of Nigella sativa and derived TQ inhibit eicosanoid generation in leukocytes and membrane lipid peroxidation. Planta Med 1995, 61:33-36.

9. Nagi MN, Mansour MA: Protective effect of TQ against doxorubicin- induced cardiotoxicity in rats: a possible mechanism of protection. Pharmacol Res 2000, 41:283-289.

10. Worthen DR, Ghosheh OA, Crooks PA: The in vitro antitumor activity of some crude and purified components of blackseed, Nigella sativa L. Anticancer Res 1998, 14:1527-1532.

11. Sayed AA, Morcos M: TQ decreases AGE- induced NF-KB activation in proximal tubular epithelial cells. Phytother Res 2007, 9:898-899. 
12. Sayed AA: TQ protects tubular epithelial cells against tubular injury. Cell Biochem Funct 2008, 26:374-380.

13. Sayed AA: Ferulsinaic acid attenuation of diabetic nephropathy. Eur J Clin Invest 2013, 43:56-63.

14. Khan N, Sultana S: Inhibition of two stage renal carcinogenesis, oxidative damage and hyperproliferative response by Nigella sativa. Eur $J$ Cancer Prev 2005, 14:159-168.

15. Sayed A: Proanthocyanidin protects against CP- induced nephrotoxicity. Phytother Res 2009, 12:1738-1741.

16. King J: The dehydrogenase of oxidoreductase-Lactate dehydrogenase. In Practical Clinical Enzymology. London, UK: Van Nostrand; 1965:83-93.

17. Sayed AA: Ferulsinaic acid modulates SOD, GSH and antioxidant enzymes in diabetic kidney. Evid Based Complement Alternat Med 2012, 10:9-15.

18. Paglia $D E$, Valentine $W N$ : Studies on the quantitative and qualitative characterisation of erythrocyte glutathione peroxidase. J Lab Clin Med 1967, 70:158-169.

19. Moron MS, Depierre JW, Mannervik B: Levels of glutathione, glutathione reductase and glutathione -S- transferase activities in rat lung and liver. Biochim Biophys Acta 1979, 67:582-589.

20. Sayed AA: Ferulsinaic acid attenuation of AGEs extends life span of Caenorhabditis elegans. J Pharm Pharmacol 2011, 12:423-428.

21. Mekheimer RA, Sayed AA, Ahmed EA: Novel 1,2,4-Triazolo [1,5-a] pyridines and their fused ring systems attenuate oxidative stress and prolong lifespan of Caenorhabiditis Elegans. J Med Chem 2012, 55:4169-4177.

22. Garrido N, Pérez-Martos A, Faro M, Lou-Bonafonte JM: CP mediated impairment of mitochondrial DNA metabolism inversely correlates with glutathione levels. Biochem J 2008, 414:93-102.

23. Green LC, Wagner DA, Glogowski J, Skipper P: Analysis of nitrate, nitrite, and $\left[{ }^{15} \mathrm{~N}\right]$ nitrate in biological fluids. Anal Biochem 1982, 162:131-138.

24. Sayed AA, El- Shaieb K, Mourad AE: Life span extension of Caenorhabditis elegans by novel pyrido perimidine drevative. Arch Pharm Res 2012, 35:69-76.

25. Morcos M, Schlotterer A, Sayed AA, Kukudov G: Rosiglitazone reduces angiotensin II and advanced glycation end product-dependent sustained nuclear factor-kB activation in cultured human proximal tubular epithelial cells. Horm Metab Res 2008, 40:752-759.

26. Fukuzawa $Y$, Watanabe $Y$, Inaguma D, Hotta N: Evaluation of glomerular lesion and abnormal urinary findings in OLETF rats resulting from a long-term diabetic state. J Lab Clin Med 1996, 128:568-578.

27. Zeashan H, Amresh G, Singh S, Rao CV: Hepatoprotective and antioxidant activity of Amaranthus spinosus against $\mathrm{CCl}_{4}$ induced toxicity. J Ethnopharmacol 2009, 125:364-366.

28. Grattagliano I, Caraceni P, Calamita G, Ferri D: Severe liver steatosis correlates with nitrosative and oxidative stress in rats. Eur J Clin Invest 2008, 11:523-530.

29. Augustyniak A, Wazkilwicz E, Krzydlewaka S: Preventive action of green tea from changes in the liver antioxidant abilities of different aged rats intoxicated with ethanol. Nutrition 2005, 6:925-932.

30. Pevni D, Frolkis I, Schwartz D: New evidence for the role of TNF-a in liver ischaemic/reperfusion injury. Eur J Clin Invest 2008, 11:649-655.

31. Zhu W, Fung PC: The roles played by crucial free radicals like lipid free radicals, nitric oxide, and enzymes NOS and $\mathrm{NADPH}$ in $\mathrm{CCl}_{4}$ - induced acute liver injury of mice. Free Radic Biol Med 2000, 29:870-880.

32. Liu LM, Zhang JX, Wang XP, Guo XH: Pim-3 protects against hepatic failure in D-galactosamine (D-GalN)- sensitized rats. Eur J Clin Invest 2010, 9:127-138.

33. Lee KC, Chan CC, Yang YY, Hsieh YC: Aliskiren attenuates chronic carbon tetrachloride- induced liver injury in mice. Eur J Clin Invest 2012 42(2):1261-1271.

34. Al-Malki AL, Moselhy SS: The protecive effect of epicatchin against oxidative stress and nephrotoxicity in rats induced by cyclosporine. Hum Exp Toxicol 2011, 30(2):145-151.
35. Al-Malki AL: Oat attenuation of hyperglycemia- induced retinal oxidative stress and NF-KB activation in streptozotocin-induced diabetic rats. Evid Based Complement Alternat Med 2012, 23:28-33.

36. Sayed AA, Khalifa M, Abdelatif FF: Fenugreek attenuation of diabetic nephropathy in alloxan-diabetic rats. J Physiol Biochem 2012, 68(2):263-269

doi:10.1186/1472-6882-14-282

Cite this article as: Al-Malki and Sayed: Thymoquinone attenuates cisplatin-induced hepatotoxicity via nuclear factor kappa- $\beta$. BMC Complementary and Alternative Medicine 2014 14:282.

\section{Submit your next manuscript to BioMed Central and take full advantage of:}

- Convenient online submission

- Thorough peer review

- No space constraints or color figure charges

- Immediate publication on acceptance

- Inclusion in PubMed, CAS, Scopus and Google Scholar

- Research which is freely available for redistribution

Submit your manuscript at www.biomedcentral.com/submit
( Biomed Central 